\title{
Effects of implementing educational program about pressure ulcer control on nurses' knowledge and safety of immobilized patients
}

\author{
Salwa A. Mohamed ${ }^{* 1}$, Soheir M. Weheida ${ }^{2}$ \\ ${ }^{1}$ Medical Surgical Nursing Department, Faculty of Nursing, Fayoum University, Fayoum, Egypt \\ ${ }^{2}$ Medical Surgical Nursing Department, Faculty of Nursing, University of Alexandria, Alexandria, Egypt
}

Received: November 10, 2014

DOI: $10.5430 /$ jnep.v5n3p12
Accepted: November 23, 2014 Online Published: December 10, 2014

URL: http://dx.doi.org/10.5430/jnep.v5n3p12

\begin{abstract}
Background: Pressure ulcers are common problems in healthcare system and produce a significant burden on patients and care providers. Hospital Acquired Pressure Ulcers is a leading cause of preventable harm. It is associated with a significant increase in treatment cost, length of stay, and poor patients' satisfaction. The aim of this study is to determine the effect of implementing educational program about pressure ulcer control on nurses' knowledge and safety of immobilized patients.

Methods: A quasi-experimental design was used to conduct the study on 40 nurses working in the critical care units at Mansoura University Hospital, in addition to 40 patients were randomly assigned from these units previous. A structured questionnaire to collect data related to socio-demographic data for nurses, pressure ulcer nurses' knowledge questionnaires, observational checklist and patient assessment sheet that include Sciodemographic data related to patients, and Braden scale sheet.

Results: The present study revealed that: (a) The mean total knowledge scores of nurses were increased immediately after implementation of a program with statistical significant difference compared to pre implementation. (b) The mean total practice scores of nurses were higher immediately after implementing program with a higher statistical significant difference compared to pre implementation. (c) There were a positive correlation between nurses' knowledge and practices with a high statistical significant difference. (d) There were a positive safety immobilized patients as evidence by less incidence of pressure ulcers among study group after received intervention than pre received intervention.

Conclusion: This study revealed that nursing staffs' knowledge and practice about pressure ulcer preventive measures could be improved. Participants in the study reported that they could use the educational program effectively and easily in the prevention of pressure ulcers among their immobilized patients, which decreases the occurrence of pressure ulcers and as well as improved patient outcome.
\end{abstract}

Recommendations: The present study recommended that continues education and in service training program for the nursing staff, which is necessary for the continuously advancing care for patients in this area.

Key Words: Pressure ulcer, Patient safety, Education, Prevention, Immobilized patients

*Correspondence: Salwa A. Mohamed; Email: sam15@fayoum.edu.eg; Address: Medical Surgical Nursing Department, Faculty of Nursing, Fayoum University, Fayoum, Egypt. 


\section{Introduction}

Pressure ulcers are lesions caused by unrelieved pressure that results in damage to the underlying tissue. Generally, these are the result of soft tissue compression between a bony prominence and an external surface for a prolonged period of time. ${ }^{[1,2]}$ The consequences of pressure-induced skin injury range from non bleachable erythema of intact skin to deep ulcers extending to the bone. The ulcer imposes a significant burden not only on the patient, but the entire health care system. Reducing the frequency of pressure ulcers is an important component of current goals for patient safety. ${ }^{[3]}$

Pressure ulcers occur over bony prominences. The most common areas for pressure ulcers include the sacrum, coccyx, heels, and ear. ${ }^{[4]}$ Pressure over a bony prominence causes tissue ischemia in the skin, muscle, and the fascia between the skin surface and bone. In addition to pressure, moisture, friction, and shear contribute to the development of pressure ulcers. Pressure ulcers remain the chief complications of prolonged hospitalization, specifically in situations of poor nutrition, increased moisture on the skin e.g., incontinence, prolonged pressure, and compromised sensory stimuli. ${ }^{[5,6]}$ Pressure ulcers increase the cost of hospitalization, increase patient morbidity and mortality, and play a significant role in the spread of infection in the clinical area. ${ }^{[7,8]}$ Stage IV pressure ulcers have a high cost, and stopping the progression of early stage pressure ulcers can significantly reduce expenditures in resource strained facilities and decrease unnecessary pain impacting thousands of patient lives. ${ }^{[7,8]}$

Prevention of pressure ulcer is always better than treating the complication associated with it, with higher expenses. Pressure ulcer occurs almost exclusively in people with limited mobility, so it is a challenge to prevent the occurrence of pressure ulcer. Pressure ulcer prevalence defined as number of clients with at least one pressure ulcer who exist in a client population at a given point in time. ${ }^{[9]}$ Pressure ulcers continue to be a safety concern in today's healthcare care systems due to the significant impact on patient outcomes and cost of treatment. It is estimated that the cost of treatment of pressure ulcers in the USA exceeds 11 billion per annum. ${ }^{[10]}$ Where there is a risk for pressure ulcer lead to development preventive interventions such as skin care practices, elimination of shear and positioning are high priorities. ${ }^{[11]}$ In study of Bours et al. ${ }^{[12]}$ assessed the prevalence of pressure ulcers and use of guidelines for prevention and treatment of pressure ulcers as importance of changing position every two hours, well-balanced nutrition, use of support surfaces and effective implementation of these guides to prevent pressure ulcers.

Patient safety is an important global issue and is recognized as a healthcare priority. ${ }^{[13]}$ Even if patient safety is a major concern for the healthcare sector, adverse events still affect

Published by Sciedu Press nearly ten percent of all patients during hospital admission, according to a systematic review. ${ }^{[14]}$ As the carer force is the main part of the sector, and as patient safety is an important issue in nursing care there is a need to develop more knowledge about pressure sores. It can cause harm and even direct cause of death in 7\%-8\% of all paraplegics. Patients hospitalized with acute illness have an incidence rate of pressure sores of $3 \%-11 \%$, which could be avoided if inadequate actions had been taken. ${ }^{[15]}$

Patient safety strategies aimed at preventing pressure ulcers may consist of individual or multicomponent interventions or a series of interventions and may include system-level changes. A systematic review by Reddy and colleagues ${ }^{[16]}$ included 59 prevention studies that addressed impaired mobility, impaired nutrition, or impaired skin health, mostly in patients in acute care settings. Healthcare agencies that implement educational programs focused on skin care and nutrition protocols to prevent pressure ulcers and intervene as early as possible have been able to demonstrate reductions in the prevalence and incidence of pressure ulcers. ${ }^{[17]}$

Nurses play a major role in prevention of pressure ulcer, as she is the one who early recognize the signs of pressure ulcer during patients stay in hospitals with immobility or fracture. She should observe for the adequate integrity of the skin and should encourage the patient to take all measurements to prevent ulcer with planned teaching programme. ${ }^{[18]}$ The process of pressure sore prevention requires skilled nursing assessment of the integumentary system and knowledge of risk factors, as well as an ongoing evaluation plan to monitor incidence and the efficacy of nursing care. ${ }^{[19]}$ Therefore, nurse make report and assessment on admission and shift change, which includes conducting a skin assessment, reinforces individual accountability in interventions to prevent development of pressure ulcers. These activities are demonstrated quality tool for identifying pressure areas before they become stage I or greater pressure ulcers. ${ }^{[20,21]}$ According to Smeltzer and Bare ${ }^{[22]}$ stated training program is a mechanism for transferring essential information to patients and caregivers. The primary focus of educational programs that deal with pressure ulcers is to translate this information into effective strategies for prevention and treatment as well as decrease cost for hospital.

\subsection{Aim of the study}

The aimed of this study is to determine the effect of implementing educational program about pressure ulcer control on nurses' knowledge and safety of immobilized patients.

\subsubsection{Operational definition}

The immobilized patient: The immobilized patient is the individual who is confined to bed, unable to move in bed or change his/her position in bed without assistance so he/she is at high risk for pressure ulcer development. 
Patient safety: Encompasses methods that protect patients from injury such as using support surfaces, regularly repositioning the patient, optimizing nutritional status, and moisturizing skin are appropriate strategies for preventing pressure ulcers and improved quality care.

\subsection{Research hypothesis}

To fulfill the aim of the study, the following research hypotheses were tested:

H1: The mean post-test knowledge score will be significantly higher than pre-test knowledge score regarding prevention of pressure ulcer among nurses.
H2: Shows no evidence pressure ulcer for patient post implementing program than pre program participants.

\section{Method}

\subsection{Research design}

A quasi experimental research design was used in the current study (pre-test/post-test design).

\subsection{Study settings}

The study has been conducted in the specialized unit (Intensive care unit, orthopedic, and neurosurgery) at Mansoura University Hospital (see Figure 1).

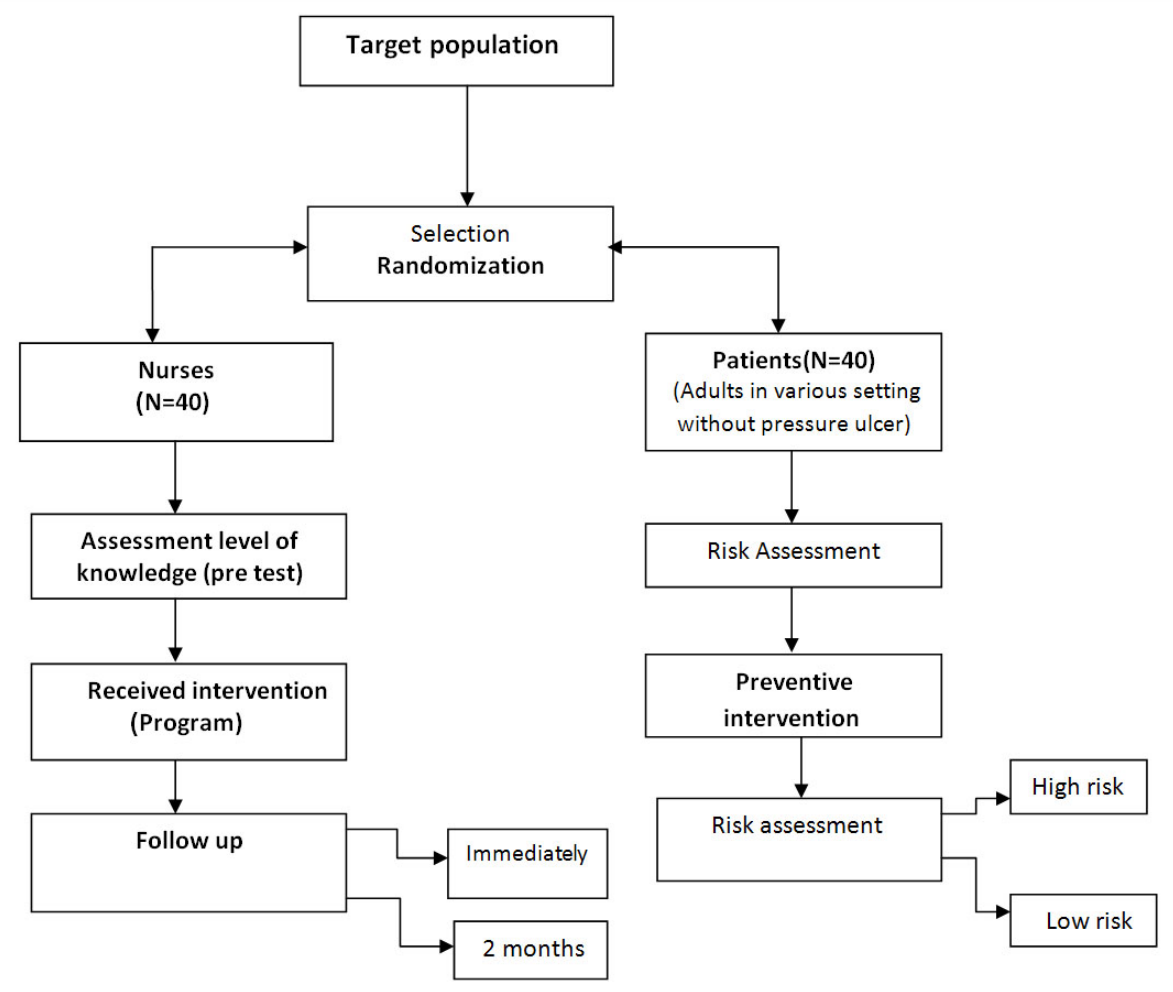

Figure 1: Recruitment and study allocation

\subsection{Study subjects}

The subjects of the present study were selected as a convenience sampling. Forty nurses were recruited into this study. The inclusion criteria were: both sex, ages from 21-60 years, working as a full time, having role and responsibility concerned with direct patient care, having educational status at least diploma in nursing, and at least 6 months of working experience on this units. In addition, 40 immobilized patients ( 20 patients from intensive care, 10 patients from orthopedic and neurosurgery) were randomly assigned into the study and they were hospitalized for more than week.
The initial sample of this study consisted of 50 patients, administered for specialized units. Forty patient were male $(80.0 \%)$ and ten patients were female $(20.0 \%)$. The criteria for selection were: patients' immobilized; patients' age ranged between 18-60 years old, length of hospital more than week and agreeing to participate in the research. Due to the prospective nature of the present study, ten patients sustained attrition out of this study. Reasons for dropout were listed under "study limitation" so only 40 patients were interviewed after ten days. The following table shows that there is no significant difference between the study group after or before excluding or dropped out cases (see Table 1). 
Table 1: Distribution of study group after and before dropped out cases

\begin{tabular}{llll}
\hline Characteristics & $\begin{array}{l}\text { Initial sample } \\
\text { N=50 }\end{array}$ & $\begin{array}{l}\text { Actual sample } \\
\mathbf{N = 4 0}\end{array}$ & $\boldsymbol{P}$ \\
\hline Sex & & & \\
Male & $15(30 \%)$ & $12(30 \%)$ & .710 \\
Female & $35(70 \%)$ & $28(70 \%)$ & \\
Mean age & $42.10 \pm 13.512$ & $41.74 \pm 12.40$ & 1.895 \\
\hline
\end{tabular}

\subsection{Tools for data collection}

The Structured Questionnaire consists of three sections:

\section{Section 1: Socio demographic data characteristics}

It was utilized for collecting relevant data characteristics such as patients' age, sex, education, income per month, marital status, and experience. Group of patients: the study was included: patients over 18 years; both genders, bedridden and stayed more than one week at hospital.

\section{Section 2: Braden risk assessment scales}

The Braden scale for predicting pressure sore risk was first introduced in 1987. ${ }^{[23]}$ It is a summated rating scale composed of six subscales: sensory perception mobility, activity, moisture, nutrition, and friction and shear. The six subscales are rated from 1 (least impaired) to 4 (most impaired), except friction and shear, which rates from 1-3. A total score range of 6 to 23 is possible, with scores of $18-23$ at low risk, 11-17 moderate risk and $<11$ as at high risk development.

\section{Section 3: Structured knowledge questionnaires}

It used to assess the nurses' knowledge of immobilized patients regarding prevention of pressure ulcer. It consists of 22 items of multiple choices questions which had been modified and developed from the pressure ulcer prevention guideline by Maylor \& Torrance, ${ }^{[24]}$ and Halfen and Eggink. ${ }^{[25]}$ These items covered knowledge about risk factors, site, stages, dressing skin care and mechanical device to reduce pressure ulcer. The total score ranged from $0-22$ and it was then covered into percentage. Each correct answer responses were given the score of one and the wrong answer was given the score of zero. The higher scores indicated the higher level of knowledge. Total score 22 $(100 \%)$, A score of $<50 \%$ was considered as unsatisfactory for knowledge and $\geq 50 \%$ score was considered as satisfactory knowledge.

\section{Section 4: Observational checklist for presurre ulcer pre- vention}

It included 22 items structured questionnaire, used to investigate the nurses' role in preventing and management

Published by Sciedu Press pressure ulcer This had been modified and developed from literature review. ${ }^{[25-28]}$ Three point numerical rating scale ranged from 1 to $3,3=$ always, $2=$ sometimes, and $1=$ never. Each items asked subjects to indicate the frequency of their practice of pressure ulcer prevention. Practice elements included factors related to pressure ulcer prevention, risk assessment, skin care, nutrition to maintain healthy skin , mangement of mechanical load and educational program for nurses. The possible scores ranged from 22-66. A score of $<50 \%$ was considered as poor. The score $<75$, score was considered pass (average) and $\geq 75 \%$ score was considered as good. The higher score indicated the higher practice .

\section{Section 5: Teaching program}

This program was planned to cover knowledge and practice for preventing and management of pressure ulcer patients, aiming to improve their health status. The content of program was developed after reviewing the following related literatures; the content was translated into Arabic. The teaching program covered information about skin care; proper positioning; nutrition and exercise as preventive measures of pressure ulcer.

\subsection{Ethical consideration}

To carry out the study, the necessary official approval was obtained from director of hospital. Written informed consents were secured from each subject to participate after explaining the nature, purpose, and benefits of the study. The researcher emphasized that participation in the study is entirely voluntary, and confidentiality and privacy were assured through coding the data.

\subsection{Validity and reliability}

It was used for modified tools such as knowledge and practice were translated and modified by the researcher. Tools content validity ascertained by jury expertise from nursing and medical staff members. The test of reliability was carried out by applying testing and retesting method which refers to administering the same test to five patients in two times, then comparing the scores obtained. There is no difference found between them. Tool reliability was $r=0.88$.

\subsection{Pilot study}

A pilot study conducted on 10 patient and 10 nurses to test clarity, simplicity and applicability of the study tool.

\subsection{Procedure}

- Official written permissions to conduct this study were obtained from the head of unit. At that time, the purpose and nature of the study were explained.

- Data collection for this study was carried out in the period from February 2013 until April 2014. 
- Data were collected throughout three phases of the assessment for nurses. The first phases of assessment was collected prior to conducting program for nurses using the two tools to have base line of data about nurses knowledge and practice about pressure ulcer, assessment was done before program implementing. The second phase of assessment was done immediately post program to evaluate the impact of program. The third phase after two months after implementing of program.

- For patients data was collected throughout two phase of assessment by using tool. The first phase of assessment was collected prior to conducting the program to assess the patients at risk for pressure ulcer condition. The second phase of assessment was collected after implementation of teaching program to evaluate improves for patients at risk.

- For proper conduction of the study, three phases were utilized:

The preparatory phase: The researcher reviewed the related literature. The designed program was developed by the researcher based on needs and requirements were translated to aims and objectives of the program. Moreover, designed questionnaires were prepared. Also each nurses and patient were interviewed individually to collect the baseline data using all study tools. Tools filling took about 30-45 minutes. The observation checklist used three times before, post and follow up and took an average of 15-30 minutes each to complete.

Intervention phase: The program was developed by the researcher based on review of current literature and research results regarding the pressure ulcer and assessment of patient knowledge and practice. A booklet containing the component of the program was written in simple Arabic language; colored booked was devolved and supplemented by photos and illustrations to help the nurses understanding of the content.

The programme consisted of 8 sessions over 2 weeks. The education intervention covered 4 hours per weeks (2/days) for each group. The teaching program was conducted in small groups (3-5 nurses/session). The lectures focused on general knowledge about pressure ulcer such as definition, symptoms, risk factor, sites, stages, treatment, devices to reduce pressure on ward, and care pressure ulcer patients. Teaching methods utilized lectures taught by the instructor, group discussions, and demonstrations. All nurse in the study group received printed materials with guidelines after each session. During the classes, nurses were encouraged to ask questions interject their own experiences and receive feedback from them.

Evaluation phase: Immediately and after 2 months after implementing programmed, each nurse was evaluated to determine the effect of the program performance of nursing using the study tools mentioned previous. The patients evaluated three times for skin assessment: 1st phase (on admission), 2nd phase (5 days) after received intervention and 3 nd phase (10 days).

\subsection{Limitation of study}

- Attrition of patients was attributed to death, and discharge from hospital, so they were excluded from study.

- Investigation findings were limited and cannot be generalized because the sample was selected from one geographical area in Egypt.

- The scope of the study was also limited not used control group.

\subsection{Statistical analysis}

Data entry and statistical analysis were done using SPSS 18.0 statistical software package. Results were presented as the frequencies, percentage, paired t-test, Pearson correlation analysis to test statistical significance of some variables and to test effectiveness of the programs. Statistical significance was considered at $p$-value $<.05$.

\section{Results}

Figure 2 reveals that the majority of the samples (80\%) were females. As shown in Figure 2, 20\% from the participants were males while the minority $20 \%$ was male.

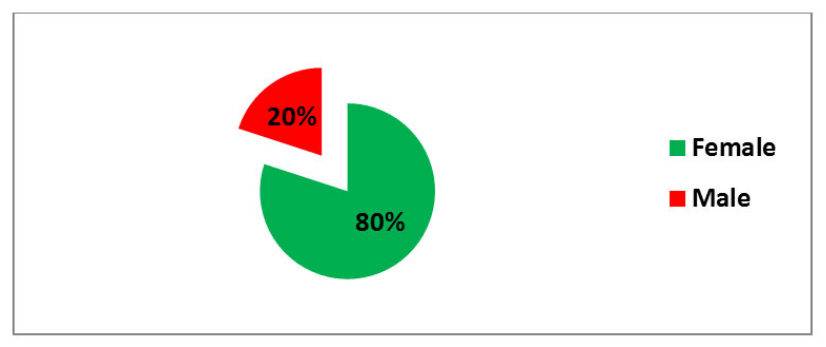

Figure 2: Distribution of studied sample in relation to gender

Figure 3 shows that the most of participants were less than 30 years. While $(25 \%)$ of participants ranged age from 30 40 years old with a mean age ( $x=24.5 \pm 3.5$ SD years). The most $(75 \%)$ of sample were married. Regarding educational status $(87.5 \%)$ had diploma in nursing. While (12.5\%) had bachelors degree in nursing. The largest number of participants were experience within 1-10 years shown in Table 2. 


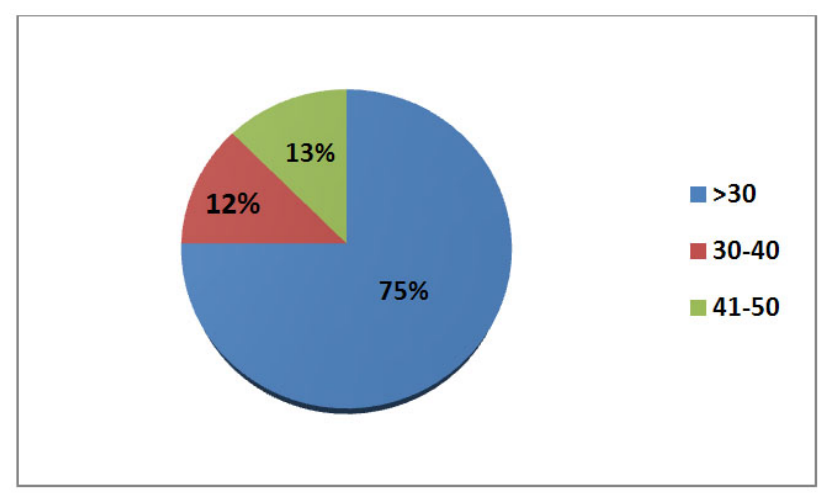

Figure 3: Distribution of studied sample in relation to gender

Table 2: Distribution of Sociodemographic characteristics of nurses

\begin{tabular}{lll}
\hline Variable & Frequency & \% \\
\hline Age & 5 & \\
$<30$ & 30 & 12.5 \\
$30-40$ & 5 & 75 \\
$41-50$ & 40 & 12.5 \\
Total & $24.5 \pm 3.5$ & 100 \\
Age years (mean ) & & \\
Educational status & 35 & \\
Diploma in nursing & 5 & 87.5 \\
Bachelor in nursing & 40 & 12.5 \\
Total & & 100 \\
Marital status & 9 & \\
Single & 30 & 22.5 \\
Married & 1 & 75 \\
Divorced & 40 & 2.5 \\
Total & & 100 \\
Experience (years) & 30 & 75 \\
$1-10$ & 8 & 20 \\
$11-20$ & 2 & 5 \\
$21-30$ & 40 & 100 \\
Total & & \\
\hline
\end{tabular}

Table 3 shows that the age of the patients ranged from 20 to 60 years, $(70 \%)$ were male. Most of patients $(52.5 \%)$ admitted to intensive care unit. Regarding hospital length of stay, the most of patients $(67.5 \%)$ were stayed the period of time ranged from (5-10) days.

Table 4 shows that $80 \%$ (32 patients) of all patients were at risk for pressure ulcers based on the total score of the Braden scale with $\leq 20$ pre application of program, while the lowest prevalence among patients 30\% (12 patients ) after implementing of programs and slightly elevated after 10 days.

Table 3: Description of sample in relation to socio-demographic characteristics of patients

\begin{tabular}{lll}
\hline Socio-demographic data & No (40) & \% \\
\hline Age & 6 & \\
$20-29$ & 8 & 15 \\
$30-39$ & 14 & 20 \\
$40-49$ & 12 & 35 \\
$50-$ & 40 & 30 \\
Total & & 100 \\
Gender & 28 & \\
Male & 12 & 70 \\
Female & 40 & 30 \\
Total & & 100 \\
Admitted to & 21 & \\
Intensive care unit & 9 & 52.5 \\
Neurosurgery & 10 & 22.5 \\
Orthopedic & 40 & 25 \\
Total & & 100 \\
Length of hospital stay(days) & & \\
5-10 & 27 & 67.5 \\
$11-15$ & 10 & 25 \\
$>15$ & 3 & \\
Total & 40 & \\
\hline
\end{tabular}

Table 4: Mean Barden scale score before, immediately, and follow up implementing program

\begin{tabular}{|c|c|c|c|c|}
\hline \multirow{3}{*}{ Assessment phase } & \multicolumn{4}{|c|}{ Barden scale } \\
\hline & \multicolumn{2}{|c|}{$<17$ (moderate risk) } & \multicolumn{2}{|c|}{$>17$ (low risk) } \\
\hline & $\mathbf{N}$ & $\%$ & $\mathbf{N}$ & $\%$ \\
\hline Before(on admission) & 32 & 80 & 8 & 20 \\
\hline Immediately ( 5 days) & 12 & 30 & 28 & 70 \\
\hline Follow up ( 10 days) & 15 & 37.5 & 25 & 62.5 \\
\hline Before $\& 5$ days & \multicolumn{4}{|c|}{$7.418 \& p<.05$} \\
\hline Before $\& 10$ days & \multicolumn{4}{|c|}{$5.383 \& p<.05$} \\
\hline 5 days $\& 10$ days & \multicolumn{4}{|c|}{$3.671 \& p<.05$} \\
\hline
\end{tabular}

Table 5 reveals frequencies and percentages of nurses knowledge regarding pressure ulcer pre- post test and follow up test. There are difference between pre and post test percentage of knowledge as regard to identification of pressure ulcer, management of pressure ulcer, and prevention of ulcer $(47.5 \%, 55 \%$, and $40 \%$, respectively) on pre test compared to $(90 \%, 97.5 \%$, and $95 \%$, respectively) in the post test (after intervention). There are significant difference between pre, post test and follow up ( 2 months) of nurses knowledge regarding pressure ulcer $(p$-value $<.05)$. 
Table 5: Percentage distributions of nurses' knowledge pre, post, and follow up program implementation $(\mathrm{N}=40)$

\begin{tabular}{|c|c|c|c|c|c|c|c|}
\hline \multirow{2}{*}{ Items } & \multicolumn{2}{|c|}{ Pre test } & \multicolumn{2}{|c|}{ Post test } & \multicolumn{2}{|c|}{ Follow up } & \multirow{2}{*}{$\boldsymbol{P}$} \\
\hline & $\mathbf{N}$ & $\%$ & $\mathbf{N}$ & $\%$ & $\mathbf{N}$ & $\%$ & \\
\hline Concepts of pressure ulcer: & & & & & & & $<.05$ \\
\hline Satisfactory & 19 & 47.5 & 36 & 90 & 31 & 77.5 & \\
\hline Un satisfactory & 21 & 52.5 & 4 & 10 & 9 & 22.5 & \\
\hline Management of pressure ulcer: & & & & & & & $<.05$ \\
\hline Satisfactory & 22 & 55 & 39 & 97.5 & 36 & 90 & \\
\hline Un satisfactory & 18 & 45 & 1 & 2.5 & 4 & 10 & \\
\hline Pressure ulcer preventive measure: & & & & & & & $<.05$ \\
\hline Satisfactory & 16 & 40 & 38 & 95 & 35 & 87.5 & \\
\hline Un satisfactory & 24 & 60 & 2 & 5 & 5 & 12.5 & \\
\hline
\end{tabular}

Figure 4 shows that most of nurses $(77.5 \%)$ had unsatisfactory knowledge regarding pressure ulcer pre test, while the majority of participants (87.5\%) after application of the program. this improvement was partially lost $(80 \%)$ during follow up assessment.

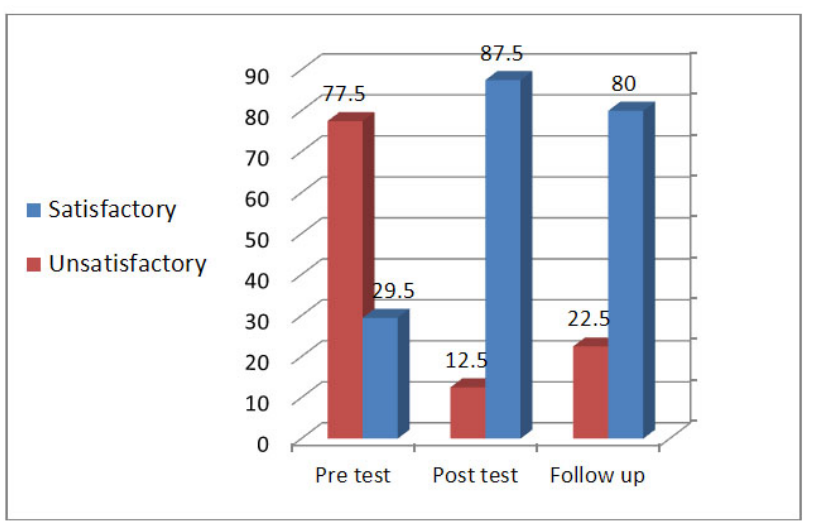

Figure 4: Percent Distribution of nurses' knowledge

Table 6 shows that the distribution of practice score in the studied sample. In pretest, the maximum $(62.5 \%)$ of the subjects received the score (poor); $17.5 \%$ of subjects re- ceived the score (pass) and $20 \%$ of the subjects received the good score in study group. While posttest, the more than half $(57.5 \%)$ of the participants received the score (good) and $30 \%$ of the subjects received the score (pass), only $10 \%$ were poor score in the study group.

Table 6: Distribution of overall practice score

\begin{tabular}{|c|c|c|c|c|c|c|}
\hline \multirow{3}{*}{ Items } & \multicolumn{6}{|c|}{ Practice score } \\
\hline & \multicolumn{2}{|c|}{ Pre test } & \multicolumn{2}{|c|}{ Post test } & \multicolumn{2}{|c|}{ Follow } \\
\hline & $\mathbf{N}$ & $\%$ & $\mathbf{N}$ & $\%$ & $\mathbf{N}$ & $\%$ \\
\hline Poor & 25 & 62.5 & 5 & 10 & 10 & 25 \\
\hline Pass & 7 & 17.5 & 12 & 30 & 16 & 55 \\
\hline Good & 8 & 20 & 20 & 57.5 & 14 & 20 \\
\hline Total & 40 & 100 & 40 & 100 & 40 & 100 \\
\hline
\end{tabular}

Table 7 shows that there is a significant correlation between knowledge and practice with age during post and follow up assessment $(r=0.481$ and 0.361 at $p<.05)$. In relation to practice, there is a significant correlation between practice and age post and follow up program $(r=0.325$ and 0.337 at $p<.05)$. While there are no statistically significant relations between education, experience and knowledge and practice $(p>.05)$.

Table 7: Correlations between socio demographic data and patients' knowledge and practice pre, post and follow up the implementation program

\begin{tabular}{|c|c|c|c|c|c|c|}
\hline \multirow{3}{*}{ Items } & \multicolumn{3}{|l|}{ Knowledge } & \multicolumn{3}{|l|}{ Practice } \\
\hline & Before & After & Follow up & Before & After & Follow up \\
\hline & $R(P)$ & $R(P)$ & $R(P)$ & $R(P)$ & $R(P)$ & $R(P)$ \\
\hline Age & $0.692(>.05)$ & $0.481(<.05)$ & $0.361(<.05)$ & $0.238(>.05)$ & $0.325(<.05)$ & $0.337(<.05)$ \\
\hline Education & $0.237(>.05)$ & $0.491(>.05)$ & $0.560(>.05)$ & $0.247(>.05)$ & $0.788(>.05)$ & $1.513(>.05)$ \\
\hline Experience & $0.451(>.05)$ & $0.672(>.05)$ & $0.786(>.05)$ & $1.023(>.05)$ & $0.655(>.05)$ & $0.451(>.05)$ \\
\hline
\end{tabular}

\section{Discussion}

The incidence and management of pressure ulcers in hospitalized patients is an ongoing concern for nurses. Efforts to prevent pressure ulcer development are plagued with inconsistencies and a general lack of best practice guidelines. Establishing current practice approaches to the assessment, prevention and management of pressure ulcers is a neces- 
sary first step in the implementation of evidence-based/best practice guidelines. ${ }^{[29]}$ So the study aimed to determine the effect of implementing educational program about pressure ulcer control on nurses' knowledge and safety of immobilized patients

The results of the present study showed that the most of nurses' aged less than thirty years and the majority of nurses experience less 10 years. These findings are consistent with El-Sayed et al. ${ }^{[30]}$ who stated that nurses' age mostly ranged from 20 to 25 years with a mean duration of experience of $25.4 \pm 11.6$ months.

The present study stated that the majority of all patients at risk for pressure ulcer based on total score of Barden scale before implementing the program will be decrease after received intervention on 5 days and 10 days. This might be attributed to the satisfactory impact of the educational program on nurse's performance and patient's outcome. This finding is consistent with Aljezawi ${ }^{[31]}$ who found a significance difference in nursing care provided by nurses and patients' that developed on admission $\&$ after 10 days. This result agrees with Hagisawa \& Barbenel ${ }^{[32]}$ whom reported that interesting study from Japan was published in the Journal of the Royal Society of Medicine). Pressure ulcer prevalence and incidence were assessed in 275 patients, either who were admitted to a well-staffed internal medicine ward during a 12-month period or who were present on day 1 of the study. Patients scored as being at high risk on the Braden scale (score 16 or less) received active preventive care, weekly assessment and continuous monitoring. This finding supported with a cohort study was conducted in Omaha to determine the incidence of pressure ulcers and relationship between risk level and demographic characteristics, diagnosis and prescription of preventive interventions. A total of 843 patients were selected randomly, who did not have pressure ulcers on admission. A head to toe skin assessment for pressure ulcer, recording sites and stages of ulcers, score for the Braden scale for predicting pressure sore risk, demographic characteristics and primary diagnosis and preventive interventions were documented on the patient record. The result showed that $12.8 \%$ subject developed pressure ulcers. The incidence was $8.5 \%$ in tertiary care, $7.4 \%$ in Veteran's Administration Medical Centers and $23.9 \%$ in nursing homes respectively. ${ }^{[33]}$

Our results of the present study stated that the knowledge among nurses about identification of risk factor of pressure ulcer, management and preventive measures for pressure ulcer are moderate level. Similarly to the study of Meesterberends et al. ${ }^{[34]}$ who found that the knowledge among nurses employed in Dutch hospitals about the usefulness of preventive measures is moderate. Poor knowledge about these measures was also found by several other authors. ${ }^{[35,36]}$ Clay $^{[37]}$ found that pressure ulcer prevention and management is beneficial not only to patients but also to the health care system, so education for healthcare profes- sionals is an important factor in the prevention and management of pressure ulcers. Hence, adequate knowledge about pressure ulcer preventive strategies is important, these were also reflected frequently used in practice.

The current study showed that the nurses' knowledge regarding pressure ulcer were improved after implementing of program. This result supported by the work of Smith \& Waugh et al. ${ }^{[38]}$ who used descriptive study among 435 registered nurses. The Pieper Pressure Ulcer Test was used to assess the nurses' knowledge. Found the significance of this study is a nurse's knowledge were significantly higher when exposed to educational material. In Egypt, study by El Enein \& Zaghloul, ${ }^{[39]}$ who using a descriptive crosssectional study with 122 subjects. This study demonstrated that, unless a nurse had received pressure ulcer education within the past year, his/her knowledge was below the minimal acceptable standards. Significantly higher scores were obtained when pressure ulcer education was available. This attributed to nurses providing information about skin care and preventive measures help to maintain skin integrity has great benefit.

The present study revealed that the nurses' practice regarding pressure ulcer was at the average (pass) level. This attributed to workload, shortage of nurses, inadequate facilitate. This result agrees with Hadley \& Roques ${ }^{[40]}$ who reported that moderate level of practice among staff may be related to certain factors, first, the shortage of nursing staff, limited time of patients care.

In relation to the practice about pressure ulcer, results revealed that gained higher scores of pressure ulcer related practice after participation in the educational program in the study group. This result consistent with the findings of Abd Alla $^{[41]}$ who reported improving the nurses' knowledge and skills after implementation of in service program to pressure ulcer. On the other hand, preventive interventions (nutritional supplementation; repositioning; pads and dressings; lotions, creams, and cleansers) for patients at high risk for pressure ulcer was more effective than usual care in preventing pressure ulcer.

The study showed that a statistically significant correlation between level of knowledge and practice for the study group post implementation of program. This finding is inconsistent by what was detected by Wilkers et al. ${ }^{[42]}$ who found that there was no relationship between Hong Kong nurses knowledge and practice. Although the majority of nurses had good knowledge regarding pressure ulcer prevention but their practice was reported to be at a low level. This finding was similar to a previous study that found that nurses' high level of knowledge regarding pressure ulcer prevention intervention was not reflected into practice. ${ }^{[43]}$ Also Maylor ${ }^{[44]}$ conducted study among orthopedic nurses, found had a negative correlation between knowledge and practice of pressure ulcer. 
In the present study there are statistically correlation between age and knowledge and practice among the studied nurses. This may be attributed to active and fresh knowledge. While there was no statistically significant correlation between education levels, experience of nurses and knowledge and practice of pressure ulcer prevention and management among the studied nurses.

\section{Conclusion and recommendations}

In conclusion, this study found that educational program is highly effective in improving knowledge and practice for nurses in critical unit as well as patient outcome. Based on the findings of the current study, it is recommended that further research is needed to consider the routine use and regular revision of pressure ulcer risk assessment sheet should be encouraged, obstacles with regard to the implementation of pressure ulcer preventive measures should be recognized and addressed to achieve a change in practice and there is a need to plan an in service training program for the nursing staff, which is necessary for the continuously advancing care for patients in this area.

\section{Acknowledgements}

I express my gratitude and thanks towards all who have directly or indirectly helped me to complete this study and their support in each major step of the study.

\section{Conflicts of Interest Disclosure}

The author declares that there is no conflict of interest statement.

\section{References}

[1] Thomas DR. The new F-tag 314: prevention and management of pressure ulcers. J Am Med Dir Assoc. 2006; 7: 523. PMid:17027631 http://dx.doi.org/10.1016/j.jamda.2006.05.008

[2] Sibbald RG, Krasner DL, Woo KY. Pressure ulcer staging revisited: superficial skin changes \& Deep Pressure Ulcer Framework (C). Adv Skin Wound Care. 2011; 24: 571. PMid:22101483 http: //dx.doi.org/10.1097/01.ASW.0000408467.26999.6d

[3] Duncan KD. Preventing pressure ulcers: the goal is zero. Jt Comm J Qual Patient Saf. 2007; 33: 605. PMid:18030862

[4] Perry. P. "Fundamentals of Nursing", 7th edition, 2009, Missouri, Elsevier. 2009; 1228-31.

[5] Allman, R. M. Pressure ulcer prevalence, incidence, risk factors, and impact, Clinics in Geriatric Medicine. 1997; 13(3): 421-36. PMid:9227937

[6] Allman, R. M. Goode, P. S. Patrick, M. M. Burst, N. Bartolucci, A. A. "Pressure ulcer risk factors among hospitalized patients with activity limitation," Journal of the American Medical Association. 1995; 273(11): 865-70. PMid:7869557 http://dx.doi.org/10. 1001/jama.1995.03520350047027

[7] Holm, B. Mesch, L. and Ove, H. Importance of nutrition for elderly persons with pressure ulcers or a vulnerability for pressure ulcers: a systematic literature review, Australian Journal of Advanced Nursing. 2007; 25(1): 77-84.

[8] Bliss M. and Simini, B. "When are the seeds of postoperative pressure sores sown?" British Medical Journal. 1999; 319(7214): 86364. http://dx.doi.org/10.1136/bmj . 319.7214.863

[9] Wound Ostomy and Continence Nurses (WOCN) Society: Clinical Practice Guideline Series: Guidelines for Prevention and Management of Pressure Ulcers. Glenview, IL: WOCN Society.

[10] Gray-Siracusa, K., Schrier, L. Use of an intervention bundle to eliminate pressure ulcers in critical care. Journal of Nursing Care Quality. 2011; 26(3): 216-25. PMid:21278597 http://dx.doi.org/1 $0.1097 / \mathrm{NCQ} .0 \mathrm{~b} 013 \mathrm{e} 31820 \mathrm{e} 11 \mathrm{be}$

[11] Eckman K. The prevalence of dermal ulcers among persons in the U.S. who have died. Decubitus. 1989; 2: 36-40. PMid:2787653

[12] Brous,G.J., Halfen, R.J.G., Abu-Saad, H.H, Groll, R.T.P. Prevelance , prevention and treatmentof pressure ulcers: Descriptive study in 89 instituions in the Netherlands, research in Nursing and health. 2002; 25: $99-110$

[13] WHO. World alliance for patient safety forward program. 2005. Available from: http://www.who.int/patientsafety/en/b rochure_final.pdf
[14] de Vries, EN., et al. The incidence and nature of in-hospital adverse events: a systematic review. Quality \& Safety in Health Care. 2008; 17(3): 216-223. PMid:18519629 http://dx.doi.org/10.1136 /qshc. 2007.023622

[15] De Meester, K., Van Bogaert, P., Clarke, SP., Bossaert, L. In-hospital mortality after serious adverse events on medical and surgical nursing units: a mixed methods study. Journal of Clinical Nursing. 2013; 22(15-16): 2308-17. PMid:22827923 http://dx.doi.org/10. $1111 / j .1365-2702.2012 .04154 . x$

[16] Reddy M, Gill SS, Rochon PA. Preventing pressure ulcers: a systematic review. JAMA. 2006; 296: 974-84. PMid:16926357 http: //dx.doi.org/10.1001/jama.296.8.974

[17] Lyder, C. H., Ayello, E. A. Pressure Ulcers : A Patient Safety Issue. In Patient Safety and Quality: An Evidence-Based Handbook for Nurses. 2005; 268-299).

[18] Ingnataricius.D. Donna, et al. "Medical Surgical Nursing. A Nursing Process Approach", 2nd edition, 1995, Philadelphia, W.B.Saunder Company. 1995; 1935-44.

[19] Gosnell D: Assessment and evaluation of pressure sores. Nursing Clinics of North America. 1997; 22(2): 399-415.

[20] Crumbley DR, Kane MA. Development of an evidence-based pressure ulcer program at the National Naval Medical Center: Nurses' role in risk factor assessment, prevention and intervention among young service members returning from OIF/OEF. Nurs Clin North Am. 2010; 45: 153-168. PMid:20510701 http://dx.doi.org/1 $0.1016 / j$. cnur.2010.02.009

[21] Perry D, Borchert K, Burke S, et al. Institute for Clinical Systems Improvement. Pressure Ulcer Prevention and Treatment Protocol. January 2012.

[22] Smeltzer Connell., Bare ,BG, Hinkle J.L. Brunner and Suddarth: A textbook of medical surgical nursing 12th ed. Lippincotts and willikins. USA. 2012.

[23] Braden BJ. Objectives I: risk factor identification. The relationship between stress and pressure sore formation. Ostomy/Wound Manage. 1998; 44 (Spec Suppl): 26S-40S. PMid:9625996

[24] Maylor, M.and Torrance, C. Pressure ulcer survey part 2 : nurses knowledge . Journal of word care. 1999; 8: 101-5.

[25] Halfen,R.J.G., Eggink, M.C. Knowledge ,belief and use of nursing methods in preventing pressure sores in Dutch hospital. International Journal of nursing Studies. 1995; 32: 16-62. http: //dx.doi.org/10.1016/0020-7489(94)00032-F

[26] CBO, Toetsing CbvdI: Richtlijn Decubitus .Guideline on Pressure Ulcers. Centraal Begeleidingsorgaan voor de Intercollegiale Toetsing (Dutch Institute for Healthcare Improvement): Utrecht, 2002. 
[27] Gunningberg L. Pressure ulcer prevention: evaluation of an education programme for Swedish nurses. Journal of Wound care. 2004; 13(3): 85-9. http://dx.doi.org/10.12968/jowc.2004.13.3 .26587

[28] Streiner DL, Norman GR. Health Measurement Scales: A Practical Guide to their Development and Use. 3rd edition, Oxford University Press. 2003.

[29] Shahin ES, Dassen T, and Halfens RJ. Incidence, prevention and treatment of pressure ulcers in intensive care patients: a longitudinal study. Int J Nurs Stud. 2009 Apr; 46(4): 413-21. PMid:18394626 http://dx.doi.org/10.1016/j.ijnurstu.2008.02.011

[30] El-Sayed., Mohamed, Z.A.E, Mohamed, Y.W. and El-Sonbaty, A.M. Impact of in service training program on bed sores identification prevention and management among immobilized patients. Ass. Univ. Bull. Environ. Res. 2003; 6(1): 133-145.

[31] Aljezawi.M. Exploring preventive interventions and risk factors of hospital-acquired pressure ulcers: a retrospective matched casecontrol design,published doctorate thesis, De Montfort University, 2011.

[32] Hagisawa S and Barbenel J. The limits of pressure sore prevention. Journal of the Royal Society of Medicine. 1999; 92: 576-578. PMid:10703495

[33] Bergstrom Braden B, Kemp M, Champagne M, Ruby E. Multisite incidence of pressure ulcers and relationship between Risk level and demographic characteristics, diagnosis, and prescription of preventive intervention. Journal of American Geriatric Society. 1996; 44(1): 22-30.

[34] Meesterberends E., Halfens R., Heinz C., Lohrman C., and Schols J. Pressure ulcer incidence in Dutch and german NursingHomes:Design of Prespective multicenter chorot study. BMC nurse. 2011; 10: 8. PMid:21526990 http://dx.doi .org/10.11 86/1472-6955-10-8

[35] Pancorbo-Hidalgo PL, Garcia-Fernandez FP, Lopez-Medina IM \& Lopez-Ortega J. Pressure ulcer care in Spain: nurses' knowledge and clinical practice. Journal of Advanced Nursing. 2007; 58: 327-
338. PMid:17442040 http://dx.doi.org/10.1111/j.1365-2 $648.2007 .04236 . \mathrm{x}$

[36] Miyazaki MY, Caliri MH \& Santos CB. Knowledge on pressure ulcer prevention among nursing professionals. Revista LatinoAmericana de Enfermagem. 2011; 18: 1203-1211. http://dx.d oi.org/10.1590/S0104-11692010000600022

[37] Clay L. Nursing Economics. 2007; 25(5): 267-269.

[38] Smith, D. \& Waugh, S. Research study: an assessment of registered nurses' knowledge of pressure ulcers prevention and treatment. Kansas Nurse. 2009; 84(1): 3-5.

[39] El Enein, N.Y., Zaghloul, A.A. Nurses' knowledge of prevention and management of pressure ulcer at a Health Insurance Hospital in Alexandria. International Journal of Nursing Practice. 2011; 17(3): 262-68. PMid:21605266 http://dx.doi.org/10.1111/j .1440-172X.2011.01933.x

[40] Hadley, M. B., Roques, A. Nursing in Bangladesh: Rhetoric and reality. Social Science and Medicine. 2007; 64: 115365. PMid:16884841 http://dx.doi.org/10.1016/j.socscim ed. 2006.06.032

[41] Abd-Allah SM. Assuring quality care through a managerial in service training program for head nurses working in Assiut University Hospital. Unpublished doctorate dissertation, Faculty of nursing, Assiut University. 2000.

[42] Wilkers,L.M., Bostock,E.,Lovitt, L., Dennis,G. NursesKnowldgeof pressure ulcer management in elderly people. Britsh journal of nursing. 1996; 5: 858-68. http://dx.doi.org/10.12968/bjon.1 996.5 .14 .858

[43] Pancorbo-Hidalgo, P. L., Garcia-Fernandez, F. P., Lopez-Medina, I. M., \& Lopez- Ortega, J. Pressure ulcer care in Spain: Nurses' knowledge and clinical practice. Journal of Advanced Nursing. 2007; 58: 327-38. PMid:17442040 http://dx.doi.org/10.11 11/j.1365-2648.2007.04236.x

[44] Maylor, M. Control belief of orthopedic nurses in relation to knowledge and prevelance of pressure ulcers. Journal of orthopedic nursing. 2001; 5: 180-85. http://dx.doi.org/10.1054/joon. 20 01.0181 